\title{
PENGARUH SELF CONTROL, FINANCIAL LITERACY DAN PARENTAL SOCIALIZATION TERHADAP SAVING BEHAVIOR
}

\author{
Jennifer dan Ary Satria Pamungkas \\ Program Studi Manajemen Fakultas Ekonomi Universitas Tarumanagara, Jakarta \\ Jennifer.115160205@stu.untar.ac.id
}

\begin{abstract}
The purpose of this study is to find out about the influence of self control, financial literacy, parental socialization can affect saving behaviour. This study uses the generation $Z$ at Jakarta as many as 219 respondents and analyzed with SmartPLS 3.2.8. Those samples are collected with google form and use convenience sampling method. The results of this study indicate that self control, financial literacy and parental socialization can affect saving behavior and all of these variable have positive relationship toward saving behaviour.
\end{abstract}

Keywords: Self Control, Financial Literacy, Parental Socialization, Saving Behavior.

Abstrak: Tujuan dari penelitian ini adalah untuk mengetahui dan menganalisis pengaruh kontrol diri, literasi keuangan dan sosialisasi orang tua terhadap perilaku menabung. Penelitian ini menggunakan sampel yaitu pada generasi Z di Jakarta sebanyak 219 responden dan dianalisa dengan SmartPLS 3.2.8. Sampel diperoleh melalui google form dan pemilihan sampel yang digunakan adalah teknik convenience sampling. Hasil penelitian ini menunjukkan bahwa kontrol diri, literasi keuangan dan sosialisasi orang tua memiliki pengatruh terhadap perilaku menabung dan seluruh variabel memiliki hubungan yang positif terhadap perilaku menabung.

Kata kunci: Kontrol diri, Literasi Keuangan, Sosialisasi Orang Tua, Perilaku Menabung.

\section{LATAR BELAKANG}

Kehidupan di kota besar terkadang menjadi penyebab individu merasa sulit untuk menghindari pola hidup konsumtif. Penghasilan yang diperoleh di rasa tidak dapat mencukupi kebutuhan, jika individu tidak memiliki kemampuan dalam mengendalikan diri berkaitan dengan keuangan. Pemahaman mengenai kebutuhan mana yang harus dijadikan prioritas merupakan suatu hal yang nyata dalam kehidupan manusia di masa sekarang dan berdampak pada masa depan.

Saat menentukan keputusan menabung diperlukan pengetahuan tentang keuangan yang dapat membantu pola pikir individu agar dapat menyadari betapa pentingnya untuk memiliki kesadaran menabung. Dengan timbulnya pemikiran bahwa menabung dapat membantu mengatasi permasalahan yang tidak terduga dimasa depan maka individu akan memperoleh keputusan keuangan yang bijaksana dan bertanggung jawab

Arahan dan pengetahuan dini dari orang tua yang lebih berpengalaman sangat penting agar generasi muda dapat mulai menabung sejak usia dini dan diharapkan akan terus berlanjut. Dengan menyisihkan sebagian uang saku dari orang tua dapat membantu membentuk pola perilaku menabung seseorang. 


\section{KAJIAN TEORI}

Teori yang digunakan dalam penelitian ini adalah Theory of Planned Behavior. Theory of Planned Behavior (TPB) merupakan perluasan dari Theory of Reasoned Action (TRA). Theory of Planned Behavior (TPB) dirancang untuk memprediksi dan menjelaskan perilaku manusia dalam konteks tertentu menurut Azjen (1991). Faktor yang dianggap penting dalam Theory of Planned Behavior (TPB) adalah niat yang dimiliki individu untuk melakukan suatu perilaku tertentu.

Theory of Planned Behavior (TPB) mengasumsikan bahwa niat merupakan untuk mengungkapan faktor-faktor motivasi yang dapat mempengaruhi perilaku dengan indikasi berupa bagaimana individu berusaha keras untuk mencoba, seberapa besar upaya yang akan dilakukan untuk melaksanakan rencana yang telah dibuat untuk menjalankan perilaku.

Ada tiga konsep yang terdapat dalam Theory Planned Behavior (TPB) yaitu Attitude Towards the Behavior, Subjective norm dan Perceived Behavioral Control. Pertama, Attitude Towards the Behavior mengarah pada tingkat dimana seseorang menentukan evaluasi positif atau negatif terhadap perilaku. Sementara itu, Subjective norm mengarah pada tekanan sosial yang dirasakan saat melakukan atau tidak melakukan perilaku tersebut. Sedangkan untuk Percieved Behavioral Control mengarah pada persepsi orang tentang kemampuan yang dimiliki dalam melakukan perilaku tertentu.

\section{Hubungan antar Variabel dan Kerangka Pemikiran}

\section{Kaitan antara Self Control terhadap Saving Behavior}

Self Control atau pengendalian diri merupakan kemampuan yang dimiliki seorang individu dalam membuat dan melakukan keputusan keuangan sehingga dapat sesuai dengan tujuan keuangan yaitu untuk menabung dalam berbagai bentuk apapun. Ketika individu mempunyai pengendalian diri yang maka semakin baik juga keputusan keuangan yang dimiliki dan perilaku menabung. Pada penelitian Thung et al. (2012); Sirine dan Utami (2016); Tharanika dan Andrew (2017); Marwati (2018) menyatakan bahwa terdapat pengaruh Self Control terhadap Saving Behavior.

\section{Kaitan antara Financial Literacy terhadap Saving Behavior}

Financial Literacy didefinisikan sebagai pengetahuan yang memadai tentang keuangan pribadi, fakta dan ketentuan untuk pengelolaan keuangan pribadi yang sukses. Dengan semakin luas pengetahuan atau kemampuan mengenai keuangan maka semakin baik juga keputusan yang dihasilkan. Menurut Thung et al. (2012); Jamal et al. (2015); Sirine dan Utami (2016); Tharanika dan Andrew (2017); Rachma (2019) terdapat pengaruh dari Financial Literacy terhadap Saving Behavior.

\section{Kaitan antara Parental Socialization terhadap Saving Behavior}

Parental Socialization merupakan pengertian, nilai dan didikan yang dimiliki individu dan diperoleh secara langsung dari orang tua dan berkaitan dengan cara berperilaku dalam masyarakat serta dalam perilaku menabung yang terkait dengan keuangan. Sosialisasi orang tua yang berkembang dengan baik pada diri individu akan membantu individu untuk mempunyai perilaku menabung yang kompeten. Menurut Thung et al (2012); Sirine dan Utami (2016); Marwati (2018) terdapat pengaruh Parental Socialization terhadap Saving Behavior. 


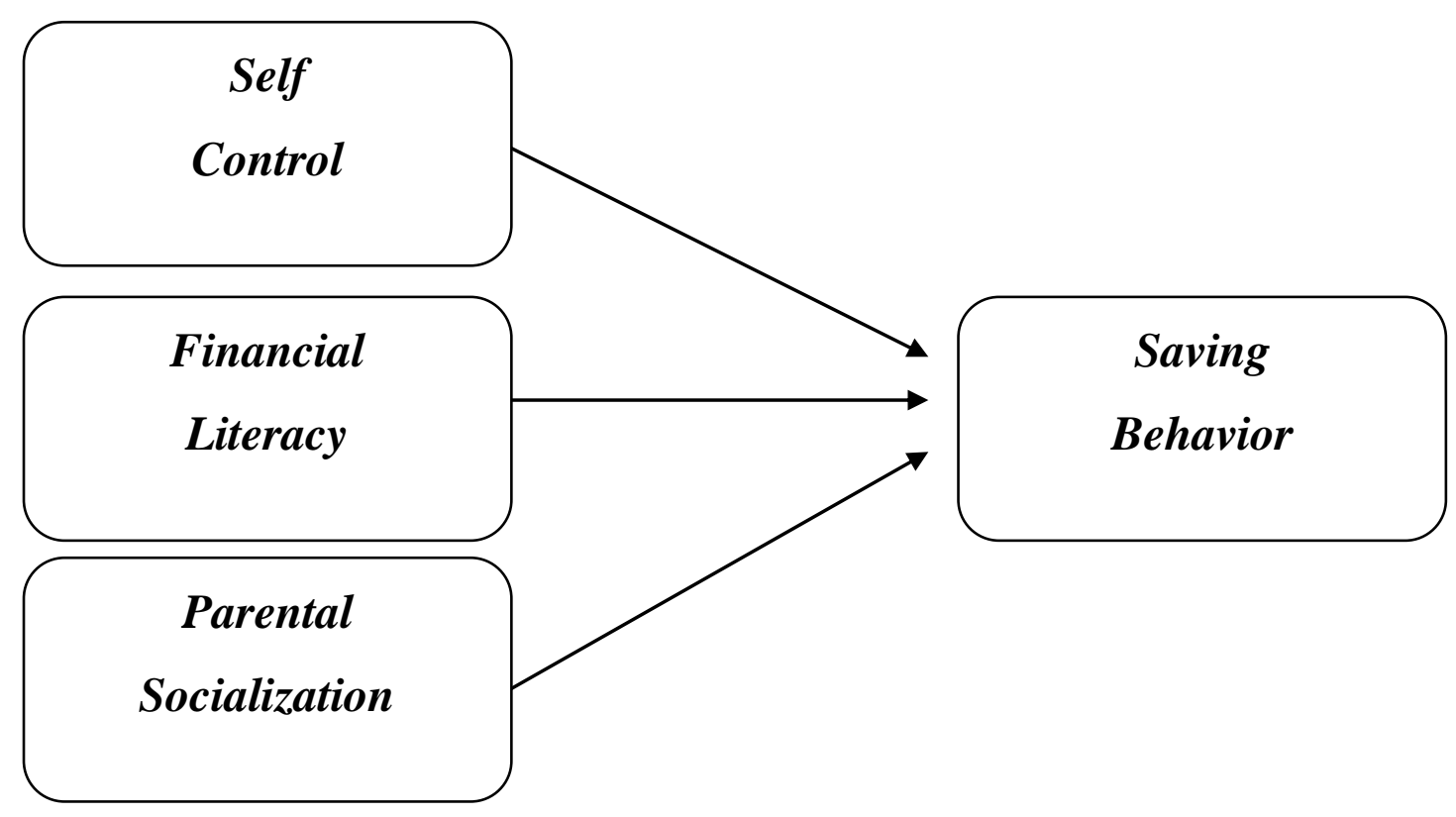

Gambar 1. Model Penelitian

Dalam penelitian ini, hipotesis dapat dirumuskan sebagai berikut:

H1 : Terdapat pengaruh Self Control terhadap Saving Behavior.

H2 : Terdapat pengaruh Financial Literacy terhadap Saving Behavior.

H3 : Terdapat pengaruh Parental Socialization terhadap Saving Behavior.

\section{METODOLOGI}

Desain penelitian yang digunakan dalam penelitian ini adalah desain penelitian deskriptif. Desain penelitian deskriptif digunakan untuk meneliti populasi atau sampel tertentu dalam jumlah besar, pengumpulan data menggunakan instrumen penelitian serta analisis data bersifat kuantitatif atau statistik, dengan tujuan untuk menguji hipotesis yang telah ditetapkan. Metode pengambilan sampel yang digunakan dalam penelitian ini adalah nonprobability sampling, yaitu merupakan teknik pemilihan sampel yang tidak memberikan kesempatan atau peluang yang sama pada setiap anggota populasi untuk dijadikan sebagai sampel

Populasi dalam penelitian ini adalah generasi $\mathrm{Z}$ di Jakarta yang sudah memiliki penghasilan dengan sampel dalam penelitian ini berjumlah 219 responden. Teknik pengambilan sampel yang digunakan dalam penelitian ini adalah teknik convenience sampling, yaitu teknik pemilihan sampel dari orang yang paling mudah dijumpai atau diakses. Pengumpulan data dilakukan dengan menyebarkan kuesioner yang disajikan dalam Google Form yang berisi pertanyaan-pertanyaan yang terkait dengan setiap variabel dan dibagikan kepada responden melalui social media seperti line, Instagram, whatsapp, dll.

Penelitian ini menggunakan pendekatan PLS-SEM untuk mengolah data dengan software Smart PLS versi 3.2.8. Pada pengujian ini terdiri dari Self control, Financial Literacy dan Parental Socialization yang merupakan variabel independen dan Saving Behavior yang merupakan variabel dependen 


\section{HASIL ANALISIS DATA}

\section{Uji Outer Model}

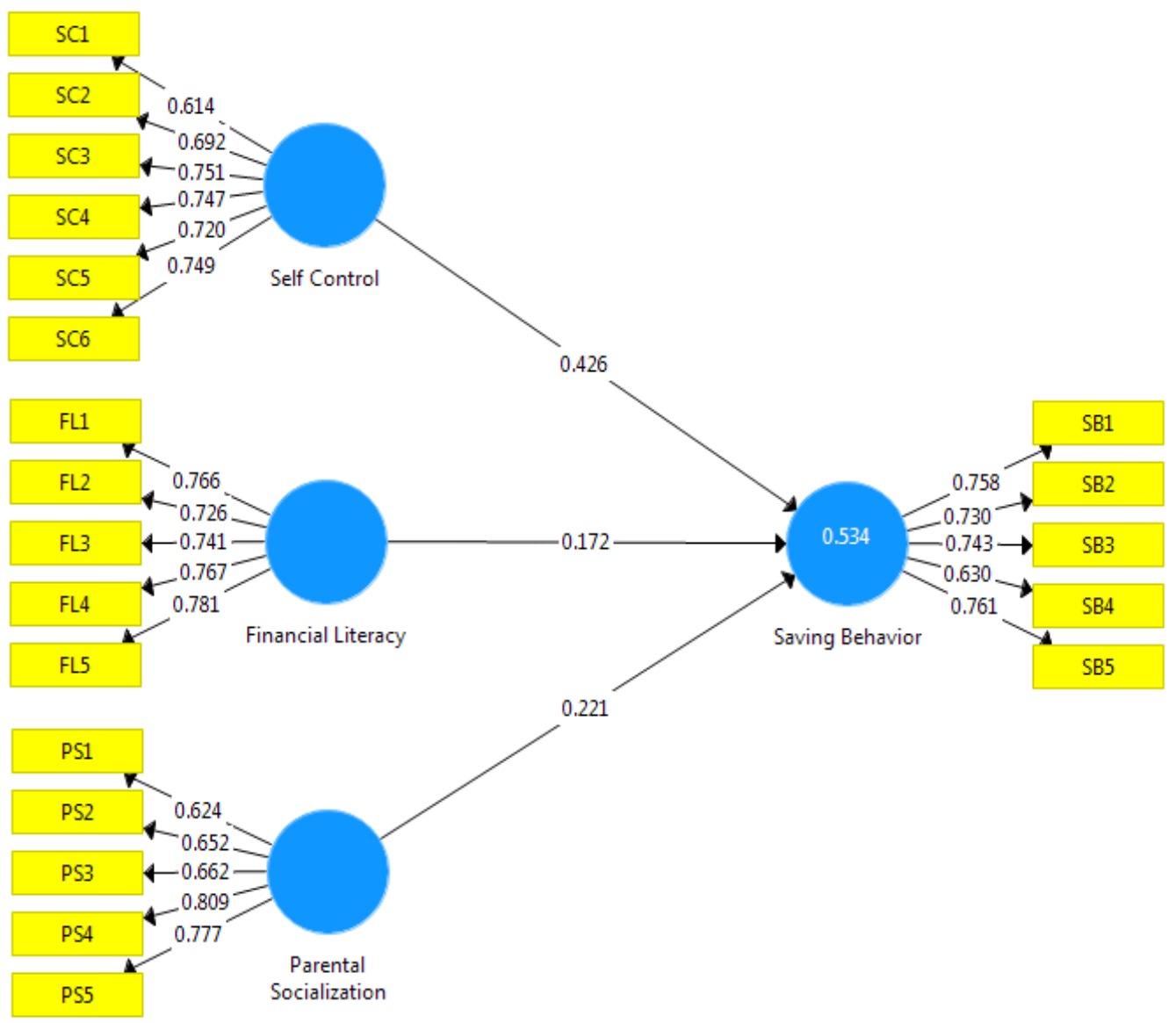

Sumber: Hasil pengolahan data dengan Software SmartPLS 3.2.8

Gambar 2. Hasil Uji SmartPLS 3.2.8

Gambar 2 menunjukkan angka dari hasil pengolahan data yang menggunakan software SmartPLS 3.2.8. Hasilnya menunjukkan bahwa seluruh indikator yang digunakan valid dan memenuhi kriteria convergent validity. 
Tabel 1. Hasil Analisis Cross Loadings

\begin{tabular}{|c|c|c|c|c|}
\hline Indikator & $\begin{array}{c}\text { Financial } \\
\text { Literacy }\end{array}$ & $\begin{array}{c}\text { Parental } \\
\text { Socialization }\end{array}$ & $\begin{array}{c}\text { Saving } \\
\text { Behavior }\end{array}$ & Self Control \\
\hline FL1 & 0.766 & 0.386 & 0.398 & 0.582 \\
\hline FL2 & 0.726 & 0.385 & 0.419 & 0.521 \\
\hline FL3 & 0.741 & 0.439 & 0.410 & 0.556 \\
\hline FL4 & 0.767 & 0.424 & 0.444 & 0.526 \\
\hline FL5 & 0.781 & 0.444 & 0.601 & 0.654 \\
\hline PS1 & 0.320 & 0.624 & 0.307 & 0.356 \\
\hline PS2 & 0.477 & 0.652 & 0.312 & 0.469 \\
\hline PS3 & 0.328 & 0.662 & 0.456 & 0.374 \\
\hline PS4 & 0.440 & 0.809 & 0.528 & 0.599 \\
\hline PS5 & 0.408 & 0.777 & 0.433 & 0.483 \\
\hline SB1 & 0.426 & 0.458 & 0.758 & 0.517 \\
\hline SB2 & 0.370 & 0.430 & 0.730 & 0.504 \\
\hline SB3 & 0.571 & 0.452 & 0.743 & 0.550 \\
\hline SB4 & 0.383 & 0.386 & 0.630 & 0.397 \\
\hline SB5 & 0.463 & 0.422 & 0.761 & 0.552 \\
\hline SC1 & 0.574 & 0.473 & 0.339 & 0.614 \\
\hline SC2 & 0.526 & 0.504 & 0.337 & 0.692 \\
\hline SC3 & 0.606 & 0.523 & 0.582 & 0.751 \\
\hline SC4 & 0.596 & 0.452 & 0.574 & 0.747 \\
\hline SC5 & 0.486 & 0.448 & 0.516 & 0.720 \\
\hline SC6 & 0.481 & 0.430 & 0.544 & 0.749 \\
\hline
\end{tabular}

Sumber: Hasil pengolahan data dengan Software SmartPLS 3.2.8

Pada Tabel 1 diatas dapat dilihat bahwa seluruh variabel telah memenuhi kriteria Cross Loading, sehingga hal ini membuktikan bahwa indikator tersebut telah memenuhi kriteria dan dikatakan valid.

Tabel 2. Hasil Uji Reliabilitas

\begin{tabular}{|c|c|c|}
\hline Variabel & Cronbach's Alpha & Composite Reliability \\
\hline Financial Literacy & 0.815 & 0.870 \\
\hline Parental Socialization & 0.752 & 0.833 \\
\hline Saving Behavior & 0.775 & 0.847 \\
\hline Self Control & 0.810 & 0.861 \\
\hline
\end{tabular}

Sumber: Hasil pengolahan data dengan Software SmartPLS 3.2.8

Pada tabel 2 diatas dapat dilihat bahwa nilai crombach's alpha $\geq 0,7$ dan composite reliability $\geq 0,7$. Hal ini membuktikan bahwa variabel tersebut telah memenuhi kriteria uji reliabilitas. 


\section{Uji Inner Model}

a. Uji Koefisien Determinasi $\left(\mathrm{R}^{2}\right)$

b.

Tabel 3. Hasil Koefisien Determinasi $\left(\mathrm{R}^{2}\right)$

\begin{tabular}{|c|c|}
\hline Variabel & R Square \\
\hline Saving Behavior & 0.534 \\
\hline
\end{tabular}

Sumber: Hasil pengolahan data dengan Software SmartPLS 3.2.8

Tabel 3 menunjukan bahwa nilai koefisien determinasi $\left(\mathrm{R}^{2}\right)$ sebesar 0,534 yang berarti sebesar 53,4\% dari variabel dependen yaitu Saving Behavior dapat dijelaskan oleh variabel independen pada penelitian ini (self control, financial literacy dan parental socialization). Pada penelitian ini, nilai koefisien determinasi $\left(\mathrm{R}^{2}\right)$ termasuk pada golongan moderate.

c. $\mathrm{Uji}$ Effect Size $\left(\mathrm{F}^{2}\right)$

Tabel 4. Hasil Uji Effect Size $\left(\mathrm{F}^{2}\right)$

\begin{tabular}{|c|c|}
\hline Variabel & Saving Behavior \\
\hline Financial Literacy & 0.027 \\
\hline Parental Socialization & 0.059 \\
\hline Self Control & 0.135 \\
\hline
\end{tabular}

Sumber: Hasil pengolahan data dengan Software SmartPLS 3.2.8

Tabel 4 disimpulkan bahwa variabel financial literacy, parental socialization dan self control memiliki efek yang tergolong kecil terhadap saving behavior.

d. $\quad$ Uji Predictive Relevance $\left(\mathrm{Q}^{2}\right)$

Tabel 5. Hasil Uji Predictive Relevance $\left(\mathrm{Q}^{2}\right)$

\begin{tabular}{|c|c|}
\hline Variabel & Predictive Relevance $\left(\boldsymbol{Q}^{\mathbf{2}}\right)$ \\
\hline Saving Behavior & 0.271 \\
\hline
\end{tabular}

Sumber: Hasil pengolahan data dengan Software SmartPLS 3.2.8

Tabel 5 menunjukkan bahwa nilai $\mathrm{Q}^{2}$ sebesar $0,271\left(\mathrm{Q}^{2}>0\right)$, sehingga kesimpulan yang dapat diperoleh adalah konstruk dari setiap variabel yang terdapat dalam penelitian ini, layak atau dapat digunakan untuk mengukur model penelitian. 
e. Uji Hipotesis

Tabel 6. Hasil Uji Hipotesis

\begin{tabular}{|c|c|c|c|}
\hline Variabel & $\begin{array}{c}\text { Path } \\
\text { Coefficients }\end{array}$ & t-statistics & p-values \\
\hline Financial Literacy -> Saving Behavior & 0.172 & 2.063 & 0.040 \\
\hline Parental Socialization -> Saving Behavior & 0.221 & 2.702 & 0.007 \\
\hline Self Control -> Saving Behavior & 0.426 & 4.589 & 0.000 \\
\hline
\end{tabular}

Sumber: Hasil pengolahan data dengan Software SmartPLS 3.2.8

a. Uji Hipotesis Pertama

H1 : Terdapat pengaruh self control terhadap saving behavior

Dari tabel 4.13, dapat diketahui bahwa nilai t-statistics dari variabel self control sebesar 4,589 (nilai t-statistics lebih besar dari 1,96) dan nilai $p$-values sebesar 0,000 (nilai $p$-values lebih kecil dari 0,05). Berdasarkan hasil tersebut maka hipotesis pertama tidak ditolak dan dapat disimpulkan bahwa terdapat pengaruh self control terhadap saving behavior.

\section{b. Uji Hipotesis Kedua}

\section{H2 : Terdapat pengaruh financial literacy terhadap saving behavior}

Dari tabel 4.13, dapat diketahui bahwa nilai $t$-statistics dari variabel financial literacy sebesar 2,063 (nilai t-statistics lebih besar dari 1,96) dan nilai p-values sebesar 0,040 (nilai p-values lebih kecil dari 0,05). Berdasarkan hasil tersebut maka hipotesis kedua tidak ditolak dan dapat disimpulkan bahwa terdapat pengaruh financial literacy terhadap saving behavior.

\section{c. Uji Hipotesis Ketiga}

H3 : Terdapat pengaruh parental socialization terhadap saving behavior

Dari tabel 4.13, dapat diketahui bahwa nilai $t$-statistics dari variabel parental socialization sebesar 2,702 (nilai $t$-statistics lebih besar dari 1,96) dan nilai $p$-values sebesar 0,007 (nilai $p$ values lebih kecil dari 0,05). Berdasarkan hasil tersebut maka hipotesis ketiga tidak ditolak dan dapat disimpulkan bahwa terdapat pengaruh parental socialization terhadap saving behavior.

\section{PENUTUP}

Penelitian ini dilakukan dengan menggunakan sampel dari 219 responden yang telah mengisi kuesioner dan telah melewati proses screening. Sehingga diperoleh responden yang merupakan generasi $\mathrm{Z}$ yang telah memiliki penghasilan dan berdomisili di wilayah Jakarta. Penelitian ini menggunakan Structural Equation Model Partial Least Square (SEM-PLS) melalui perangkat lunak SmartPLS v.3.2.8. Berdasarkan hasil penelitian disimpulkan bahwa Self Control, Financial Literacy dan Parental Socialization memberi pengaruh terhadap Saving Behavior. Dengan keterbatasan yang ada, maka saran yang dapat diberikan untuk peneliti selanjutnya agar menambahkan jumlah variabel lainnya, seperti Peer Influence atau variabel lainnya yang berkaitan. 


\section{DAFTAR PUSTAKA}

Ajzen, I. (1991). The theory of planned behavior. Organizational Behavior and Human Decision Processes, 50(2), 179-211

Dangol, J. \& Maharjan,S (2018). Parental and Peer Influence on the Saving Behavior of the Youth. International Research Journal of Management Science, 3(1), 43-63.

Fry, T.R.L., Mihajilo, S., Russel, R, \& Brooks, R. (2008). The factors influencing saving in a matched savings program: Goals, knowledge of payment instruments, and other behaviour. Journal of Family and Economic Issues, volume 29, pp 234-250.

Gerhard, P., Gladstone, J.J., Hoffmann A.O.I. (2018). Psychological Charateristics and Household Savings Behavior: The Importance of Accounting for Latent Heterogeneity. Journal of Economic Behavior and Organization, 148, 66-82.

Sekaran, U., \& Bougie, R. (2013). Research Method For Business: A Skill-Building Approach (6th Ed). West Sussex, United Kingdom: John Wiley \& Sons Ltd.

Silaen, Sofar. (2014). Metodologi Penelitian Sosial Untuk Penulisan Skripsi dan Tesis. Bogor: In Media

Sirine, H., \& Utami, D. S. (2016). Faktor-faktor yang Mempengaruhi Perilaku Menabung di Kalangan Mahasiswa. Jurnal Ekonomi dan Bisnis , 19 (1). 27-52.

Tharanika, K., \& Andrew, A. (2017). Factors Influencing On Saving Behaviour Among University Students. International Journal of Research , 4 (14). 861-871.

Thung, C. M., Kai, C. Y., Nie, F. S., Chiun, L. W., \& Tsen, T. C. (2012). Determinants of Saving Behavior among The University Students in Malaysia.

Warneryd, K.-E. (1999). The psychology of saving: A study on economic psychology. Cheltenham, UK: Edward Elgar

Wulandari, D. A. \& Susanti. (2019). Pengaruh Literasi Keuangan, Inklusi Keuangan, Uang Saku, dan Teman Sebaya Terhadap Perilaku Menabung Mahasiswa Pendidikan Akuntansi Fakultas Ekonomi Universitas Negeri Surabaya. Jurnal Pendidikan Akuntansi , 07 (2). 263- 268. 